
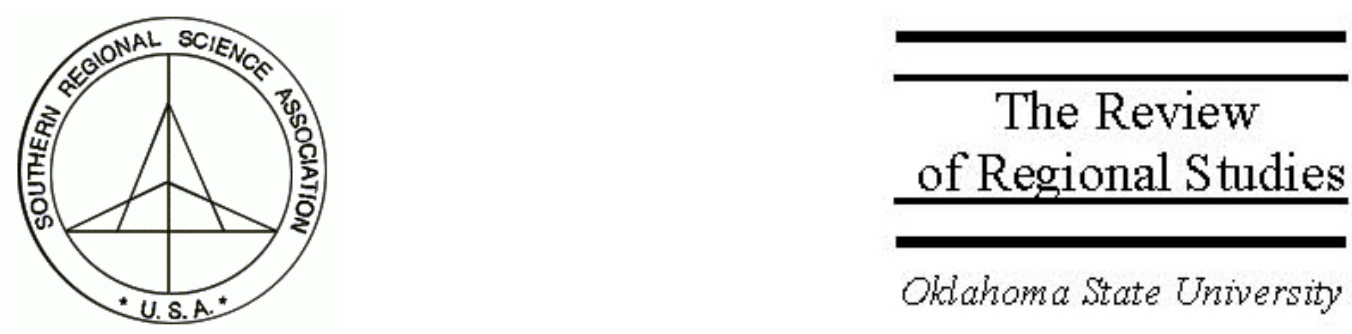

Oklahoma State University

\title{
Econometric Issues in Education Finance
}

\author{
Olugbenga Ajilore \\ Department of Economics, University of Toledo, Toledo, $\mathrm{OH} 43606-3390$, \\ e-mail: gbenga.ajilore@utoledo.edu
}

\begin{abstract}
Several econometric issues within the field of education finance that have not been fully explored to date are addressed. Focusing on demographic factors and per-pupil expenditures in the United States, an econometric model that incorporates spatial analysis is developed and a unique framework for analyzing the impact of demographics on local public demand is introduced. The results show that ethnic diversity has a negative impact on per-pupil spending, while the elderly have a positive impact.
\end{abstract}

Keywords: Education finance; Endogeneity; Spatial dependence

JEL classification: I22; H75

The author thanks Cecilia Conrad and James Lesage for assistance and Kristen Keith, Kevin Egan, the editor, and two anonymous referees for helpful comments and suggestions. 


\section{INTRODUCTION}

This paper introduces a framework for analyzing the impact of demographics on local public demand, focusing within the growing field of demographic structure and education finance. This field considers issues such as what determines a district's support for public education; whether the size of the elderly population may play a role; and how much, if at all, a district's demographics may explain differences in school outcomes. However, there is no consensus to date on the relative influence of these factors. The objective of this paper is to provide the proper framework for achieving some answers. I test the hypothesis that a district's diversity affects support for public education, using the standard measure of per-pupil spending as the dependent variable, and address the econometric issues within this debate, namely regressor endogeneity and the existence of spatial dependence, by estimating a variety of models using county-level data from the 2000 Census.

While theory has explained why endogeneity may be an issue, whether the variables in question are endogenous has not been explicitly tested. Also, with regard to spatial dependence, I evaluate whether the level of per-pupil spending of neighboring counties affects a given county's spending. Based on these assessments, I develop a model that corrects for endogeneity and incorporates spatial dependence. The results show that ethnic diversity has a negative impact on per-pupil spending, while the elderly have a positive impact. The following section provides a brief review of the literature. Section 3 outlines the econometric issues. Section 4 describes the data and methodology. Section 5 provides the results, and Section 6 briefly discusses these results and offers some concluding remarks.

\section{LITERATURE}

There is a burgeoning literature on the local public demand for education. This literature has its roots in studies on the demand for public goods, beginning with Bergstrom and Goodman (1972) and Borcherding and Deacon (1972). These works established a functional form used to estimate the demand for public spending, which has since been applied to education spending. Using a survey of Michigan households, Bergstrom, Rubinfeld, and Shapiro (1982) tested both the Tiebout hypothesis and the median voter hypothesis. The Tiebout hypothesis states that people choose their residential location by the amount of public spending in the given location, i.e., citizens "vote with their feet." The median voter hypothesis proposes that the preferred level of spending will be that of the median voter because that level of spending will garner the most support in an election. The authors found smaller income and price elasticities than had been found in earlier macro-level studies. Further work used this data to correct for specification issues (see Rubinfeld, Shapiro, and Roberts 1987).

More recently, a number of scholars have tested the proposition that the proportion of elderly has a negative impact on public education funding. Poterba (1997), using a panel data set of U.S. states, found that an increase in the proportion of elderly in a population 
decreased per-pupil expenditures on education and that the size of this effect increased with an increasing percentage of nonwhite students. However, more recent work has cast doubt on this result. Ladd and Murray (2001) posit that earlier works were flawed in that sorting decisions of the elderly were not separately estimated. They argued that location choices made by the elderly are not independent of the education spending level and thus using a single equation to estimate the influence of the elderly on school funding causes endogeneity problems. ${ }^{1}$ Using county-level panel data and a two-stage least squares (2SLS) regression, they found no significant impact of the elderly on per-pupil spending. Harris, Evans, and Schwab (2001) conducted a similar analysis on a panel data set of school districts and found evidence of a negative effect, though to a lesser extent than Poterba (1997).

The impact of heterogeneity on the demand for public education can be addressed using the median voter theory as the basis for a model. Following Alesina, Baqir, and Easterly (1999), if the median voter determines expenditure per pupil and if ethnic groups differ in their preferences for education spending, then per-pupil expenditure will depend on the race of the median voter. The authors argued that heterogeneity of preferences among racial and ethnic groups can lower total spending on public goods and cited several examples where decisions about such spending differed according to race. For example, there was a heated debate about bilingual funds when a group in Oakland, California, declared "Ebonics" a distinct language and therefore claimed that schools teaching Ebonics would be eligible for these funds. Asian American and Hispanic groups argued vehemently against the initiative. If a large fraction of the population has preferences that are quite different from those of the median voter, they will vote to spend less on the public good and allocate more of their resources to private consumption.

While most theories predict that ethnic diversity will negatively impact education spending, increased ethnic diversity may lead to greater public spending. According to the growth of government literature, ${ }^{2}$ government officials will increase spending on public goods in order to accommodate various interest groups. Peltzman (1980) developed a rent-seeking model where increased inequality led to higher levels of government spending. Therefore, to ensure accurate estimations of the effects of ethnic diversity on public spending, the measure must take into account these different factors and preferences. The measure of diversity is discussed in more detail in Section 4.

\section{ECONOMETRIC ISSUES}

\subsection{Endogeneity}

Ordinary Least Squares (OLS) estimation may be inappropriate for estimating the impact of local public demand on education finance because spending on local public

\footnotetext{
${ }^{1}$ Rubinfeld, Shapiro, and Roberts (1987) refer to this as the "Tiebout bias" in single-equation models of local public demand functions.

${ }^{2}$ See Holsey and Borcherding (1997) for a detailed review.
} 
goods depends on a number of variables such as ethnic diversity and the proportion of elderly in a population. ${ }^{3}$ Poterba $(1997$, p.52) stated, "Studying local jurisdictions brings a different set of empirical problems because the demographic composition of a small community cannot be viewed as exogenous, but rather depends on the structure of local public spending." ${ }^{4}$ The argument is that the level of public education spending is a factor in the decision to live in a given school district or county. Ladd and Murray (2001) addressed this problem by estimating a two-stage least squares (2SLS) model in which the proportion of elderly was instrumented. They posited that the proportion of elderly in a region is a function of education quality, number of school-aged children, proximity to jobs, and environmental quality. Harris, Evans, and Schwab (2001) addressed this issue by using the population aged 55 to 64 from the previous Census year as an instrument. In addition to the elderly variable, I tested the endogeneity of ethnic diversity.

While none of the above-mentioned works explicitly test for endogeneity, there is a body of literature that discusses instrumental variables estimation and the development of specification tests. Baum, Schaffer, and Stillman (2003) outlined the issues with instrumental variables estimation and discussed test procedures for endogeneity, overidentification, and heteroskedascity. In this study, I used two diagnostic tests, the Durbin-WuHausman test for endogeneity of a specific regressor and the Sargan test for validity of the instruments. ${ }^{5}$ These tests can be used in both cross-sectional and panel data models. It is important to test for endogeneity because it leads to weak instruments that tend to produce estimates that are not robust to changes in specifications.

\subsection{Spatial Dependence}

Spatial econometrics provides models for situations where sample data observations are taken with reference to points or regions on a map. Such data often exhibit spatial dependence as the actions in one region impact those in a neighboring region. The equation for a spatial econometrics model that takes this impact into account follows:

$$
y=\rho^{*} W^{*} y+X^{*} \beta+\varepsilon,
$$

where $y$ is a function of the neighboring counties' $y$ and a series of $X \mathrm{~s} .^{6}$ This specific model is called the spatial autoregressive (SAR) lag model. $W$ represents the spatial weight matrix that quantifies the relationship between the observations. If $\rho$ is significantly different from zero, then the data exhibits spatial dependence, indicating that the actions in one region impact those of a neighboring region. There are a variety of

\footnotetext{
${ }^{3}$ Ibid, 1.

${ }^{4}$ Poterba (1997) does not account for this because the analysis was performed on state-level data.

${ }^{5}$ The test used was the Sargan test for overidentifying restrictions, which Davidson and MacKinnon (1993) argue can also be used to test for the validity of instruments. Shea Partial $\mathrm{R}^{2}$ also tests instrument validity (Shea 1997).

${ }^{6}$ This is not the only model that incorporates spatial dependence. See Anselin (2001) for a detailed review of the literature.
} 
methods for specifying the weight matrix $W$, including using the relationship between observations based on Euclidean distances (a nearest-neighbors matrix) or assigning values of 1 if counties are adjacent and 0 otherwise (first-order contiguity matrix). Equation (1) can be rewritten so that $y$ is a function of the $X$ s and the error term, as follows:

$$
y=\left(I-\rho^{*} W\right)^{-1} * X^{*} \beta+\left(I-\rho^{*} W\right)^{-1} * .
$$

$\left(\mathrm{I}-\rho^{*} \mathrm{~W}\right)^{-1}$ can be rewritten as an infinite sum to help explain the potential impact of spatial dependence, as follows.

$$
y=X^{*} \beta+\rho^{*} W^{*} X^{*} \beta+\rho^{2 *} W^{2 *} X^{*} \beta+\rho^{3 *} W^{3 *} X^{*} \beta+\ldots,
$$

where the first term expresses the direct impact of the explanatory variables on the dependent variable and all other terms represent indirect impacts via neighbors. More specifically, the second term is the impact of the explanatory variables through first-order neighbors, and the third term is the impact through second-order neighbors, and so on. Because $\rho$ is between 0 and 1 , the indirect impacts decrease in size. Taking spatial dependence into account may have important implications for the analysis. I test for this using the significance of the parameter estimate for $\rho$.

\section{DATA AND METHODOLOGY}

The basic equation used for model estimation follows Poterba (1997) and Ladd and Murray (2001), where the log of per-pupil expenditures is the dependent variable and $Z$ is a matrix of explanatory variables that may affect the demand for education spending. Most studies that have considered the impacts of race and ethnicity on local public goods used the percentage of the nonwhite population as a proxy for race. While this might address the impact on spending of race in general, it does not accurately reflect how the dynamics of race have changed over the last 30 years. With an increase in minority groups such as Latino and Asian populations, diversity has taken on new dimensions. Scholars have begun to use a new measure of diversity based on linguistic diversity developed by Lieberman (1969). This measure is the probability that two persons chosen at random from a given population will be of a different race or ethnicity. The calculation is as follows.

$$
\text { Diverse }=1-\Sigma\left(\pi_{i}\right)^{2}
$$

where $\pi_{i}$ is the proportion of the population of ethnicity $i$. Higher values mean that the population is more diverse. For example, if the county were comprised only white individuals, the probability of randomly choosing two individuals of different races would be 0 , because $\pi_{i}$ would be equal to 1 . If the county were composed of whites and blacks only and evenly, the probability of randomly choosing two different races would be 50 percent. 
The other explanatory variables included Percent Owner-Occupied, which serves as a proxy for the after-tax price of education spending. Poterba (1997) related this to the deduction of state and local taxes from federal income taxes. Normally, tax price is calculated as the share of residential value in the community divided by the total value in the community. However, there are many econometric problems with using the standard measure of tax price in the estimation procedure that Percent Owner-Occupied bypasses. Also included as explanatory variables are the share of school district revenue from the state government and per-child federal aid. While it might seem that such intergovernmental measures would be vulnerable to endogeneity problems, aid is generally through a block grant or based on revenue-raising capacity, not on how much is spent in a given county.

Percent Youth measures the composition of the population between ages 5 and 17 . Median Household Income is included to measure the capacity of the district to spend on public goods in general. To account for the size of the county, the log of the number of households is included. The share of the county population with a high school diplomas and those with college degrees are also included. Percent Urban is typically used to account for differences in the cost of schooling between urban and rural areas. Ladd and Murray (2001) restricted their sample by excluding rural counties because Percent Urban would have been $0 .^{7}$ To avoid this complication, I used the Beale Index from the U.S. Department of Agriculture, which is a scale from 1 to 9 that measures the degree to which a region is classified as urban or rural with 1 being the most urban and 9 being the most rural. Finally, I included the relative proportions of ethnic groups. Vigdor (2002) argued that including this variable allows one to estimate the impact of individual groups on spending separately from the community composition.

The dependent variable used in the model is Per-Pupil Spending (PPS), which measures local public demand for education. The hypothesis is that the higher the PPS, the more a district supports public schooling. Other scholars have used PPS as a measure of educational quality, but this view has proven controversial. Many (e.g., Hanushek, Rivkin, and Taylor 1996) argue that increased spending does not translate into improved school outcomes. While PPS may represent a proxy for the quality of education, the link does not seem strong enough for interpretative purposes. However, PPS does seem to measure public support because there is a general belief that higher spending will improve educational outcomes.

PPS and the other financial variables are derived from the 2000 Census County Government Finances. Demographic variables are taken from the Census Bureau and then merged with the financial data. Counties without children or with a public school enrollment of less than 100 students were excluded. Except for the Beale Index, all variables are logged. Table 1 summarizes the variables.

\footnotetext{
${ }^{7}$ Since all the explanatory variables are logged, rural counties would have to be excluded.
} 
TABLE 1

\begin{tabular}{lccccc}
\multicolumn{7}{c}{ Summary of Variables } \\
\hline \multicolumn{1}{c}{ Variable } & OBS & Mean & SD & Min & Max \\
\hline Per-Pupil Spending & 3,081 & $7,640.62$ & $1,910.25$ & $4,116.69$ & $38,219.93$ \\
Diverse & 3,081 & 0.246 & 0.18 & 0.011 & 0.732 \\
Households & 3,081 & 32,927 & 101,879 & 202 & $3,133,774$ \\
Median Income & 3,081 & $32,560.16$ & $7,953.83$ & $14,178.00$ & $77,513.00$ \\
\% Owner & 3,081 & 0.74 & 0.07 & 0.27 & 0.90 \\
Beale Index & 3,081 & 5.11 & 2.67 & 1 & 9 \\
College & 3,081 & 0.17 & 0.06 & 0.05 & 0.45 \\
\% Elderly & 3,081 & 0.08 & 0.02 & 0.01 & 0.18 \\
\% Youth & 3,081 & 0.19 & 0.02 & 0.09 & 0.34 \\
\% Black & 3,081 & 0.09 & 0.14 & 0 & 0.86 \\
\% Native & 3,081 & 0.01 & 0.06 & 0 & 0.93 \\
\% Asian & 3,081 & 0.01 & 0.02 & 0 & 0.31 \\
\% Latino & 3,081 & 0.06 & 0.12 & 0.00 & 0.98 \\
Per-Child Federal Aid & 3,081 & 573.28 & 434.99 & 0.00 & $8,259.26$ \\
State Revenue Share & 3,081 & 0.55 & 0.14 & 0.02 & 0.86 \\
\hline
\end{tabular}

The main variable of my analysis was Diversity. However, I also considered the effect of the elderly population on PPS as it compares to earlier findings. As described earlier, increased heterogeneity should decrease support for education spending. Therefore, the coefficient of ethnic diversity should be negative.

\section{RESULTS}

\subsection{Endogeneity}

As previously mentioned, there may be endogeneity issues with both the Elderly and Diversity variables. The decision to locate within a county may depend on the size of these populations so that using OLS will provide biased estimates. ${ }^{8}$ To identify suitable instruments, it is important to use measures that are correlated with endogenous variables but not with other explanatory variables. Common measures used as instruments include prior census values of potential endogenous variables. The Elderly variable was instrumented by size of the population aged 55 to 64 ten years prior. Literature on the residential habits of the elderly has shown that once they are settled in a house, they are likely to remain there (Schafer 1999). Thus, the size of the elderly population in the year 2000 should be a function of the population of that group ten years earlier. The instrument for the Diversity variable was the 1990 value for Diversity. There are a number of reasons to expect a given county's distribution of minorities to be relatively consistent over time.

${ }^{8} \mathrm{I}$ also tested the endogeneity of Median Income but could not reject the null hypothesis of exogeneity. 
For example, minorities may be restricted in residential mobility due to housing discrimination. Also, minorities might feel more comfortable living in areas with a sizable minority population.

The Durbin-Wu-Hauman (DWH) statistic for Elderly was 0.306 with a p-value of 0.579 , and the DWH for Diversity was 8.595 with a p-value of 0.003 . The null hypothesis, namely, that the regressor would be exogenous, was rejected for Diversity but not for Elderly. The Pagan-Hall test statistic was 528.037; therefore, we can reject the null hypothesis that the disturbances were homoskedastic. To correct for this, I used the efficient GMM estimator, which is robust in the presence of heteroskedasticity. Table 2 shows the results of both the OLS and instrumental variables (IV) estimations.

I ran several tests to evaluate the validity of the instruments. The Hansen J statistic (Sargan test) was 0, so the hypothesis that the instruments were valid could not be rejected. The Shea Partial $R^{2}$ was 0.039 for Diversity. While this value is low, the $F$ value was larger than 10; it can thus be concluded that the instrument is valid. The F value for Diverse was 124.45 .

Table 2 shows the importance of testing for endogeneity. In both the OLS and IV estimations, Diverse had a negative coefficient and Elderly had a positive coefficient. Comparing the estimates, the magnitude of Diverse is larger in absolute value.

TABLE 2

Instrumental Variables Estimation Results

\begin{tabular}{lrrrr}
\hline Per-Pupil Spending & \multicolumn{1}{c}{ OLS } & T-Stat & IV & T-Stat \\
\hline Diverse & -0.0434 & -5.13 & -0.1612 & -3.75 \\
Elderly & 0.1067 & 4.22 & 0.0957 & 3.65 \\
\% Owner & -0.0131 & -0.25 & -0.0190 & -0.36 \\
Median Income & 0.2823 & 6.87 & 0.3241 & 7.56 \\
\% Youth & -0.1097 & -2.61 & -0.0800 & -1.79 \\
Beale Index & 0.0030 & 1.41 & 0.0037 & 1.68 \\
Diploma & -0.0901 & -2.34 & -0.1630 & -3.32 \\
College & 0.0845 & 5.05 & 0.0827 & 4.72 \\
Federal Aid & 0.1135 & 6.16 & 0.1494 & 7.09 \\
State Share & -0.1525 & -8.47 & -0.1465 & -7.84 \\
Households & -0.0305 & -6.39 & -0.0272 & -5.21 \\
\% Black & 0.0039 & 1.19 & 0.0338 & 2.94 \\
\% Native & -0.0109 & -2.42 & 0.0106 & 1.17 \\
\% Asian & 0.0175 & 3.46 & 0.0164 & 2.86 \\
\% Latino & 0.0311 & 7.42 & 0.0726 & 4.81 \\
Constant & 5.7412 & 11.14 & 5.2055 & 9.81 \\
\hline $\mathrm{R}^{2}$ & 0.2628 &. & 0.2121 &. \\
\hline${ }^{1}$ The white population is & & & & \\
correlated with Latino. & & & & \\
& & & \\
\hline
\end{tabular}




\subsection{Spatial Analysis}

Spatial dependence was accounted for using equation (1), which considers dependence on per-pupil expenditures. I created a spatial contiguity matrix $(W)$ for the lagdependent variable using programs from the Matlab Econometrics Toolkit. ${ }^{9}$ This was deemed necessary because any given county is likely influenced by the actions of neighboring counties, and the contiguity matrix accounts for such spillover effects. Other weight matrices base the relationships among neighbors on set geographic distances. I ran a series of tests to assess whether the data exhibited spatial dependence. The Moran's $I$ test was 38.32, and thus the null hypothesis of no spatial dependence could not be rejected. The results confirmed the presence of spatial dependence, justifying the use of a spatial regression model. Florax, Folmer, and Rey (2003) described several specification tests to run against either the spatial lag model (MLLAG) or the spatial error model (MLERROR). I ran the robust version of each test; MLLAG was 5,523.85 and MLERROR was 279.039, both of which were significant. According to Florax, Folmer, and Rey (2003), the model that produces the most significant result should be used and therefore the lag model (specifically, SAR) was selected for model estimation. Table 3 shows the results of the estimation, which uses the maximum likelihood method.

TABLE 3

Estimation of SAR Model

\begin{tabular}{lrrrr}
\hline Per-Pupil Spending & \multicolumn{1}{c}{ OLS } & \multicolumn{1}{c}{ T-Stat } & \multicolumn{1}{c}{ SAR } & T-Stat \\
\hline Diverse & -0.0434 & -5.13 & -0.0214 & -3.19 \\
Elderly & 0.1067 & 4.22 & 0.0463 & 2.81 \\
\% Owner & -0.0131 & -0.25 & 0.0083 & 0.23 \\
Median Income & 0.2823 & 6.87 & 0.1593 & 6.16 \\
\% Youth & -0.1097 & -2.61 & -0.0975 & -3.65 \\
Beale Index & 0.0030 & 1.41 & 0.0009 & 0.53 \\
Diploma & -0.0901 & -2.34 & -0.0596 & -2.01 \\
College & 0.0845 & 5.05 & 0.0445 & 3.49 \\
Federal Aid & 0.1135 & 6.16 & 0.0939 & 12.33 \\
State Share & -0.1525 & -8.47 & -0.1325 & -15.28 \\
Households & -0.0305 & -6.39 & -0.0289 & -8.71 \\
\% Black & 0.0039 & 1.19 & 0.0039 & 1.73 \\
\% Native & -0.0109 & -2.42 & -0.0056 & -1.99 \\
\% Asian & 0.0175 & 3.46 & 0.0149 & 4.35 \\
\% Latino & 0.0311 & 7.42 & 0.0106 & 3.07 \\
Constant & 5.7412 & 11.14 & 1.6508 & 5.44 \\
\hline$\rho$ & & & 0.5930 & 137.16 \\
Log-Likelihood & & & $2,463.2400$ & \\
Akaike Information Criteria & & & $-4,924.500$ & \\
\hline
\end{tabular}

${ }^{9}$ The programs for running the tests and estimating the models are part of that toolkit, which can be found at http://www.spatial-econometrics.com. 
As indicated in the table, accounting for spatial dependence had implications for the results. Importantly, $\rho$ showed significance, indicating that per-pupil spending in neighboring counties has a positive effect on a given county's level of spending and that some of the effect attributed to the explanatory variables in the OLS estimation were in fact due to spatial dependence. The results shown in Tables 2 and 3 provide the framework for analysis.

\subsection{Complete Estimation}

Based on the results shown in Tables 2 and 3, the proper framework in which to estimate the impact of ethnic diversity on education spending requires a two-part procedure similar to Kelejian and Prucha (2004). First, following the first stage of a twostage least squares estimation, the exogenous variables and instruments are regressed on the Diversity variable. Then the predicted values for Diversity, together with the exogenous variables, are used to estimate the SAR model. Table 4 shows the results of the estimation procedure.

As shown in the tables, diversity has a negative and significant impact on per-pupil spending, supporting theory. Therefore, building on the discussion in Section 2, it would

\section{TABLE 4}

Estimation of SAR Model Accounting for Endogeneity

\begin{tabular}{lrrrr}
\hline Per-pupil spending & \multicolumn{1}{c}{ OLS } & \multicolumn{1}{c}{ T-stat } & \multicolumn{1}{c}{ SAR } & T-stat \\
\hline Diverse & -0.0434 & -5.13 & -0.1052 & -3.12 \\
Elderly & 0.1067 & 4.22 & 0.0382 & 2.28 \\
\% Owner & -0.0131 & -0.25 & 0.0042 & 0.12 \\
Median Income & 0.2823 & 6.87 & 0.1885 & 6.76 \\
\% Youth & -0.1097 & -2.61 & -0.0763 & -2.73 \\
Beale Index & 0.0030 & 1.41 & 0.0014 & 0.83 \\
Diploma & -0.0901 & -2.34 & -0.1114 & -3.12 \\
College & 0.0845 & 5.05 & 0.0431 & 3.46 \\
Federal Aid & 0.1135 & 6.16 & 0.1193 & 9.44 \\
State Share & -0.1525 & -8.47 & -0.1281 & -14.70 \\
Households & -0.0305 & -6.39 & -0.0266 & -7.72 \\
\% Black & 0.0039 & 1.19 & 0.0253 & 2.92 \\
\% Native & -0.0109 & -2.42 & 0.0097 & 1.47 \\
\% Asian & 0.0175 & 3.46 & 0.0142 & 4.11 \\
\% Latino & 0.0311 & 7.42 & 0.0401 & 3.29 \\
Constant & 5.7412 & 11.14 & 1.2486 & 4.37 \\
\hline$\rho$ & & & 0.5960 & 92.91 \\
Log-likelihood & & & $2,463.5900$ & \\
Akaike Information Criteria & & & $-4,925.2000$ & \\
\hline
\end{tabular}


be expected that more ethnically heterogeneous counties, after controlling for group share, would have lower per-pupil spending than other counties. Similar to the IV estimation, the coefficient on Diversity was much larger than the OLS estimation. Most of the coefficients of the spatial estimates were smaller in magnitude than those of the OLS and IV estimates, the exceptions being Diversity, Diploma, Federal Aid, and several of the group share variables. This is to be expected because the spatial parameter $\rho$ is significant. Therefore, the effect previously attributed to explanatory variables can be accounted for by the spatial parameters.

Looking more closely at the Elderly variable; the coefficient is positive and significant (Table 4). The standard hypothesis is that the elderly will not support public education because the advantages of schooling do not directly benefit them. The results shown in Table 4 contradict this hypothesis. However, recent work (e.g., Poterba 1998) has discussed the possibility that the elderly may not consider only their own direct benefit when voting on support for public education. One alternative hypothesis is that the elderly may behave altruistically when deciding on public education. Another alternative is that by supporting public education, they may attract younger residents into their district and therefore maintain property values. Brasington (1999) demonstrated that proficiency scores had a positive impact on housing values. Therefore, the coefficient of the size of the elderly population can be reconciled with the literature.

\section{DISCUSSION}

This paper contributes to the education finance literature by using spatial analysis to account for the effects of per-pupil spending by neighboring counties on a given county and explicitly testing for endogeneity. Using a national cross-section of U.S. counties, I found that ethnic diversity has a negative impact on per-pupil spending, while the elderly population has a positive effect. Ignoring spatial dependence overstates the impact of various factors and neglects the potential spillover effects of neighboring counties. The majority of the coefficients had smaller coefficients and other variables lost significance. The results from the estimation are in line with more recent work that has questioned the standard hypothesis that the elderly would not support public education and offers better estimates of the impact of demographics on per-pupil spending.

I have also shown that it is important to use tests, in addition to theory, to arrive at the appropriate methodology. Most statistical packages have readily available programs to test for spatial dependence and endogeneity where the existence of spatial dependence has proven vital. This paper has developed a framework in which to address any topic related to local public demand, especially given the wealth of available demographic and geographic data.

Future research should test this methodology at a lower unit of analysis and create a panel data set of school district data that includes variables to help test for spatial 
dependence. ${ }^{10}$ Elhorst (2003) developed a methodology and diagnostic tests for spatial analysis of panel data. Creating a panel data set with school district data will allow stronger comparisons with earlier work and further the debate on what might be the appropriate level and framework for analysis in which to discuss public education spending.

\section{REFERENCES}

Alesina, A., R. Baqir, and W. Easterly, 1999. "Public Goods and Ethnic Divisions," Quarterly Journal of Economics 114, 1243-1284.

Anselin, L., 2001. "Spatial Econometrics," in B. Baltagi (ed.), A Companion to Theoretical Econometrics. Basil Blackwell: Oxford.

Baum, C., M. Schaffer, and S. Stillman, 2003. "Instrumental Variables and GMM: Estimation and Testing," unpublished Working Paper No. 545. Boston College Department of Economics: Boston, MA.

Bergstrom, T. and R. Goodman, 1973. "Private Demands for Public Goods," American Economic Review 63, 280-296.

Bergstrom, T., D. Rubinfeld, and P. Shapiro, 1982. "Micro-Based Estimates of Demand Functions for Local School Expenditures," Econometrica 50(5), 1183-1206.

Borcherding, T. and R. Deacon, 1972. "The Demand for the Services of Non-Federal Governments," American Economic Review 62, 891-901.

Brasington, D., 1999. "Which Measures of School Quality Does the Housing Market Value?" Journal of Real Estate Research 18, 395-413.

Davidson, R. and J. MacKinnon, 1993. Estimation and Inference in Econometrics. Oxford University Press: New York.

Elhorst, J.P., 2003. "Specification and Estimation of Spatial Panel Data," International Regional Science Review 26(3), 244-268.

Florax, R., H. Folmer, and S. Rey, 2003. "Specification Searches in Spatial Econometrics: The Relevance of Hendry's Methodology," Regional Science and Urban Economics 33, 557-579.

Hanushek, E., S. Rivkin, and L. Taylor, 1996. "Aggregation and the Estimated Effects of School Resources," Review of Economics and Statistics 78(4), 611-627.

Harris, A., 1999. "Data Chapter: The Construction of a National Public School District Panel." Mimeo, University of Maryland, College Park Working Paper: College Park, MD.

Harris, A., W. Evans, and R. Schwab, 2001. "Education Spending in an Aging America," Journal of Public Economics 81, 449-472.

Holsey, C. and T. Borcherding, 1997. "Why Does the Government's Share of National Income Grow? An Assessment of the Recent Literature on the U.S. Experience," in D. Mueller (ed.), Perspectives on Public Choice: A Handbook. Cambridge University Press: New York.

\footnotetext{
${ }^{10}$ A number of authors have created panel data sets that include three years' worth of data (e.g., Hoxby 1996; Harris 1999). However, to date, no panel data sets have incorporated spatial analyses.
} 
Hoxby, C.M., 1996. "How Teachers' Unions Affect Education Production," Quarterly Journal of Economics 111(3), 671-718.

Kelejian, H. and K. Prucha, 2004. "Estimation of Simultaneous Systems of Spatially Interrelated Cross Sectional Equations," Journal of Econometrics 118, 27-50.

Ladd, H. and S. Murray, 2001. "Intergenerational Conflict Reconsidered: County Demographic Structure and the Demand for Public Education," Economics of Education Review 20(4), 343-357.

Lieberman, S., 1969. "Measuring Population Diversity," American Sociological Review $34,850-862$.

Peltzman, S., 1980. "The Growth of Government," Journal of Law and Economics 23(2), 209-288.

Poterba, J., 1997. "Demographic Structure and the Political Economy of Public Expenditure," Journal of Policy Analysis \& Management 16, 48-66. , 1998. "Demographic Change, Intergenerational Linkages, and Public Education," American Economic Review Papers and Proceedings 88, 315-320.

Rubinfeld, D., P. Shapiro, and J. Roberts, 1987. "Tiebout Bias and the Demand for Local Public Schooling," Review of Economics and Statistics 69, 426-437.

Schafer, R., 1999. "Housing America's Elderly Population." Harvard University Joint Center for Housing Studies W99-4: Cambridge, MA.

Shea, J., 1997. "Instrument Relevance in Multivariate Linear Models: A Simple Measure," Review of Economics and Statistics 49(2), 348-352.

Vigdor, J., 2002. "Interpreting Ethnic Fragmentation Effects," Economics Letters 75, 271-276. 